\title{
TAXONOMY OF TERTIARY EDUCATION CAMPUS PLANNING
}

\author{
Mohamad Jamil TERRO (1D ${ }^{1}$, Ashraf Mohamed SOLIMAN (D) ${ }^{1,2, *}$, Jerrell ANGELL (D) ${ }^{3}$ \\ ${ }^{1}$ Kingdom University, Riffa, Bahrain \\ ${ }^{2}$ Minia University, El-Minia, Egypt \\ ${ }^{3}$ University of Pennsylvania, Philadelphia, USA
}

Received 25 September 2020; accepted 05 January 2021

\begin{abstract}
This paper aims to present and discuss phases of planning and designing campuses for Higher Education Institutions (HEIs). The authors argue that creating a taxonomy to control an environment conducive to learning is of the same order of importance as that for education as depicted by Bloom, given the size, financial burden, and influence on learning outcomes. A specific model is proposed for the taxonomy of planning campuses for HEIs with four ordered phases: educational programming, spaces programming, master planning, and detailed design. The researchers followed four methodologies to support the proposed model: A literature review to seek relevant knowledge and terms used in previous studies; a descriptive discussion of the proposed campus planning and design taxonomy model; a survey of experts in educational and campus planning to examine the proposed phases; and, a case study of the campus of Kingdom University in Bahrain where the phases of taxonomy were implemented. This latter case study further exhibits how the executed campus planning process is developed in adherence with state-of-the-art educational demands and trends. This paper is concluded with guidelines of HEIs campus planning as illustrated a diagram for the proposed model of taxonomy showing the process and illustrating the model domains, together with its phases and planning process considerations. The model also analyses the relationship between the domains that are ordered according to the process flow starting with educational programming up to the detailed design phases.
\end{abstract}

Keywords: taxonomy, campus planning, design.

\section{Introduction}

The development of Higher Educational (HE) institutions is a rather complex and lengthy project that involves many participates and stakeholders including government bodies, quality assurance agencies, investment companies, educational organization, law firms, engineering and architectural design firms, contractors, and society at large. Budgets involved in such ventures are as large as the size of the project, reaching nine-digit values in U.S. dollars in its initiation and operational stages. The scope of this paper, however, is limited to the key processes involving programming, planning, and design for entire new campuses or single buildings. Therefore, the proposed design taxonomy will start at the educational program development and stop at the development of building designs.

The word "taxonomy" in the title of this paper concerned with the proposed stages of planning and design of HE campus, is used in analogy with the taxonomy for the classification of educational learning objectives coined by Benjamin Bloom in 1956 (Bloom, 1956). The proposed taxonomy for planning and design provides a roadmap that would guide the various stakeholders through the complexities involved in this rather sophisticated process. This model is based on architectural, urban and engineering principles in addition to the experience of the authors in the field of campus development phases and $\mathrm{HE}$ in general.

\section{Literature review}

The word "Campus" is originally a British term, according to Oxford Latin Dictionary, which describes a university's colleges located on one site and contains students' accommodation, teaching, learning and research facilities and rest activities all together (Glare, 1982). The term Campus became popular in the second half of the 18th century. It was used originally in European universities to identity the place where the students and academics lived and worked together in a sheltered educational environment (Chapman, 2006). Princeton University is the first university

${ }^{*}$ Corresponding author. E-mail: a.soliman@ku.edu.bh 
that used the term Campus in the United States to define the distance between colonial colleges area and the single main building of Princeton University (Yerli \& Ozdede, 2017). However, Harvard campus planned in the cloister style to reflect American values (Turner, 1984). Gul and others stated that the use of campus term is changed to include all building and open spaces within the university boundaries (Gul et al., 2016).

The word "Taxonomy" generally refers to principles and techniques of scientific classification into different ranks and categories. Scientists of biology use taxonomy principles to classify and rank the organisms such as animals, plants, viruses and bacteria (Turland \& Wiersema, 2018). Benjamin Bloom is an American educational psychologist who developed in 1950s Bloom's taxonomy for education objective classification based on knowledge, skills, and competences categories (Thomas, 2014; Bloom, 1956). The learning outcomes in Bloom's taxonomy follow an organized hierarchy starting with knowledge at its first level. Knowledge is a pre-requisite to attainment of other skills and is easily achievable through simple actions such as remembrance and comprehension of information. Skills, however, are abilities to apply knowledge. Complex actions are needed to develop skills including comprehension and analyses. Competences come last since they require, in addition to knowledge and skills, evaluation of complex information and creation of new products (Figure 1).

The authors argue that Planning and designing of campuses should adhere to specified principles, guidelines, regulations and codes. Some of these planning and design considerations are applicable to all universities while others differ from one university to another; San Diego state university (SDSU) formulated a standing committee to develop the design principles for its new campus. This committee represented the university stakeholders to ensure that it met the needs of all users. The design principles included a reflection of academic and architecture heritage of SDSU which is aligned with California mission. The investment of the mild climate of the campus location helped characterize the campus with open spaces, passages and streets and outdoor rooms for activities. The design committee developed a steward architecture to achieve multiple goals of SDSU including adoptability and flexibility over time, environmentally friendly buildings, and long-term operating costs. It promoted academic

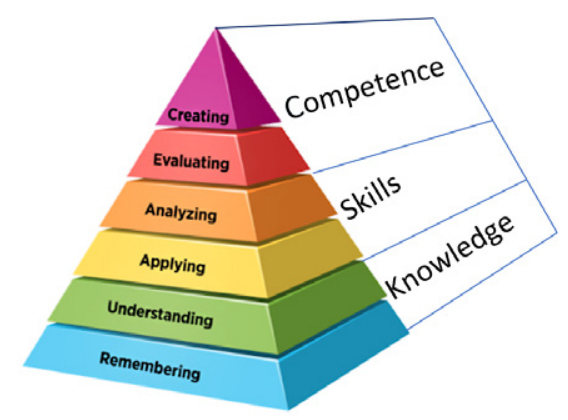

Figure 1. Hierarchy of learning outcomes endeavours in which the campus brought a diverse group of people for intellectual and social exchange, the spaces encourage stakeholders' interactions and formal and informal activates. Furthermore, the campus promoted health, wellness, diversity and connection to community through providing access for people with a variety of abilities (Schulz, 2017). The University of Georgia in Athens (UGA) focused on different design principles of the new campus such as architectural character, clusters' composition, and buildings' typology. UGA has an office of university architects for facilitating planning, which recommended design principles of the new campus of the university. Examples of adopted design principles were to avoid replicating the historic and memorable compositions of existing campus of UGA, although the design of UGA's early campus buildings is not to be underestimated as a conceptual inspiration. The new developed buildings, however, should reflect both the requirements of the moment and the traditions of architecture compatible with the context of UGA campus. The configuration of buildings was regarded as one of the vital design principles in which the buildings should be aligned with open spaces to formulate mass edge creating outdoor rooms for activates. The composition must have a balance between open space, building mass, and buildings connection among walkway to lay the campus together. The recommended design process in UGA document of design principles focused only in the detailed design phase and neglected the strategy level of consideration (Office of University Architects for Facillities Planning, 2018).

Most higher education institutions manage their campuses through their own established offices for campus services and development. The Office of Facilities and Campus Services (OFCS) in Pomona College in California developed campus planning and landscape guidelines that are aligned with the institutional goals for sustainability. The guidelines incorporate context, intent, expectations for development of sites within the campus district in addition to assessment criteria of building performance that established by American Society of Landscape Architects. The Context section addresses planning, architecture, landscape, and relationships of the college campus for the community of Claremont. The section on Intent discusses land use, building program and building regulations (Campus Planning and Landscape Guidlines, 2011). Moreover, the assessment criteria of building performance that are adhered to in Pomona college campus is categorized into four phases: Planning (site selection and site assessment), site design (water, soil, vegetation, materials, human health and well-being), construction, and management (operation, maintenance, monitoring and innovation (The sustainable sites initiative: guidelines and performance benchmarks, 2020).

The NBBJ architecture design firm stated that the master plan of a HEI must reflect the mission and vision of the institution and adhere the needs of communities it serves. NBBJ identified design principles that are followed to develop many of HEIs campuses. Design is a collaborative outcome 
in which planners, urban designers, architects, landscape architects, space planners, parking experts and engineers all together participate and integrate seamlessly to create solution of the campus master plan that address long term vision of the HEI and needs of communities (NBBJ, 2015).

As a member of the Society for Campus and University Planning, Stephen Troost stated that planning campuses must ensure the optimal use of the land with maximum utilization of the resources, meet the university's missions, aligned to strategic goals, and combine smart growth planning philosophies to ensure safety and wellness of university stockholders. He considered campus planning as an ongoing process that need guidelines on subjects that include Open space, Buildings, Non-motorized circulation, Motorized circulation, and Utilities (Troost, 2020). Furthermore, Troost articulated that planning initiatives depend on specific needs of colleges and universities. Therefore, every campus planning has different priorities for such planning initiatives. Those include architectural facilities, utilities, transportation, sustainability, maintenance, space management, and capital planning. Coulson stated that all types and sizes of HEI are already struggling to develop efficient, sustainable, and attractive environments that meet and support the academic needs of its users over the long term. Moreover, the new trend of developing the master plan of HEI aims to provide dynamic learning environment, prosperous learning spaces, and living campus against a background of haggard budgets, limited land assets and an old building standard. This trend of master planning involves four general steps: Analysis of existing buildings and environment, definition of established principles and objectives of the university, Finding out opportunities for facilities' renewal, and development of campus framework systems and related operational plans (Coulson et al., 2018).

The master plan must list overall capital priorities among whole planning period, including new construction plans, building renovations, and renewal of building functions, in addition to major maintenance priorities. The academic plan outlines the teaching and research priorities of the university, which is influenced by the building facilities, faculty and unit plan which are aligned with university vision, it and operationalize the academic priorities. The annual plan is a summary of vision, mission, and academic priorities of the university; strategic goals; capital priorities; and resources. Stack and Leitch illustrated the relationship between all planning levels of Integrated Planning Framework for HEIs, including master plan, academic plan, faculty and unit plan and annual plan. They emphasized that all these plans must relate to and influence each other (Stack \& Leitch, 2020).

In 2018, Dalton presented a review on the literature of planning and designing campus. He organized the review in 3 geographic scales: The campus-park including academic buildings facilities and landscapes; the campus-community interface including campus facilities in the campus park surrounding; and the larger campus district including campus urban context. They stated that al- though HEIs used to develop their campus to support student learning, planning researchers did not conduct sufficient experiential studies to verify achievement of this goal (Dalton et al., 2018). The pervious literature covered: Land use that supports students' learning in the campus-park, considers the campus compatibility to surrounded community, and enhances the quality of residential neighborhood in the campus district; Design that leads to cohesive buildings and landscape in the campus-park, and preserve the historical values of campus-community; Sustainability that conserve the resources of campus-park to enhance the university profit on the long term, and maintain efficient public transportation; Economic development of campus-community; and Collaboration for Joint projects with the campus-community and Preparation and implementation of district planning. Other considerations are subject to further longitudinal, comparative, and evaluative researches (Dalton et al., 2018).

An analytical study published in Journal of the American Planning Association was conducted to analyze urban form data of three U.S. campuses and the crash data that were reported by police and universities self-reports. The study is conducted to understand the spatial and sequential distribution of crashes on the campuses and their immediate border zones. The data illustrated that most of the crashes occurring inside the campus are not dangerous because campus areas are not open to cars and campus speed limits are lower. However, crashes between skateboarders, cyclists, and pedestrians are common and occurred frequently (Loukaitou-Sideri et al., 2014). Therefore, considerations for safety and security requirements for master planning of the HEIs' campuses remain an area of significance to be addressed.

\section{Proposed design taxonomy}

Four domains are proposed for the taxonomy of campus planning and design: Educational programming, space programming, master planning, and detailed design. Each domain contains a set of considerations that can be ordered progressively in terms of their importance and essentialness. In order to achieve optimum results, considerations in the domain must be addressed in a sequence - from bottom to top - in the order as shown in the pyramidal diagrams shown in Figure 2 with the description of each domain.

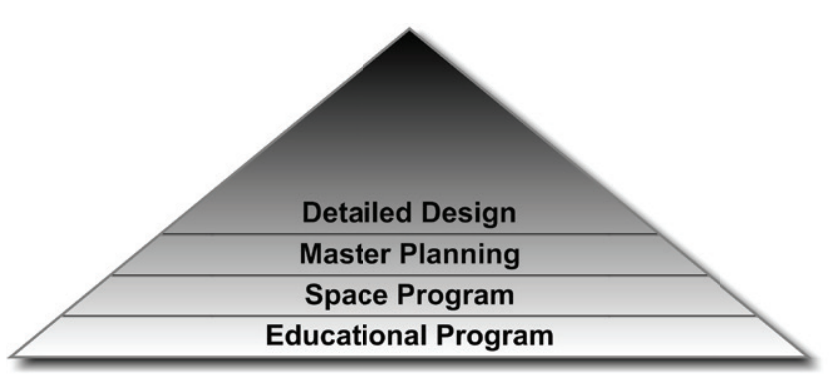

Figure 2. Domains of campus planning and design 
It could be argued that the first domain, the educational programming, should not be included in this taxonomy and that it does not match with subsequent engineering/ architectural design-based phases. However, the authors believe, based on their experience in the field, that proper campus design has to start from an in-depth study of the space program which is inseparable from adequate educational programming.

The domains or processes preceding and following the described educational and master planning and design development phases are out of the scope of this study, as previously mentioned.

\subsection{Educational programming}

Phases in this domain are depicted as follows: Vision of HE institution, society/market demand, population of the HE institution, program structure, and contact hours. Figure 3 illustrates the structure of the educational programming domain and the sequential orders and level of importance to each phase. Each phase depends on the previous one, except for the contact hours and HEI vision, as shown in right-side of the Figure 3.

\subsubsection{HE institution vision}

The vision statement of the HE institution is usually carefully considered and observed at the stage of developing an educational program. It is usually related to a higher long term political, economic, and cultural vision at the level of the country. The vision plays an important guiding role that aligns all objectives and activities within the institution. It is a primary target for inspection in institutional and academic quality assurance activities. The HEI vision is of high importance to program structure, moderate importance to market demand and population of the HEI, and low importance to contact hours, as shown in left-side of Figure 3.

\subsubsection{Society/market demand}

The output of the market study developed at the beginning of the project is consulted to decide on the fields of specialty to be considered at the HE institution. The decision on the adopted fields of study is also governed by the available and accessible teaching and training expertise. It is also necessary to gauge socioeconomic indicators to an-

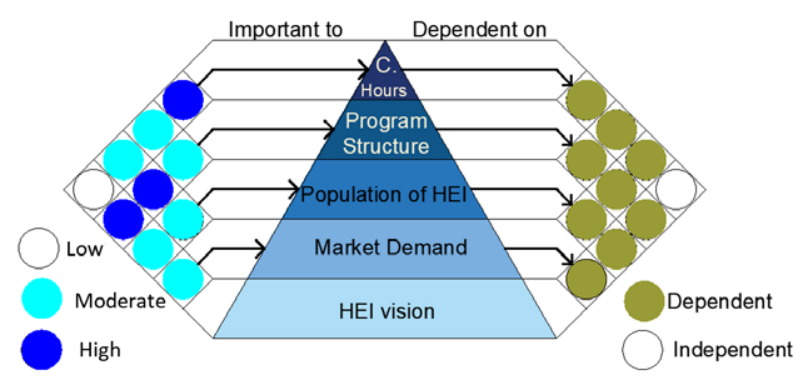

Figure 3. Educational programming domain alyze what issues need to be addressed during the student life on campus that would allow the institution to focus on the critical character traits. Pedagogical design typically involves theoretical component and practical one. That what is typically mapped into knowledge and skills development? The incorporation of competencies and/or virtues and hence the consideration in campus design is far less common. The market demand study is of high importance to program structure and moderate importance to population of the HEI and courses contact hours, as shown in left-side of Figure 3.

\subsubsection{Population of $\mathrm{HE}$ institution}

A detailed knowledge of the population of a HE institution is a major and important factor in campus planning, since they are the end users of the various facilities. It includes students, administration, faculty, assistant faculty, services employees, and visitors. The attributes of the components of the population concerned is also necessary for design purposes. Such attributes and conditions include age, sex, people with disabilities, mean of transportation, standard of living, residents on campus, in addition to social, cultural and ethnic background. For example, some countries impose gender separation rule that need to be taken into account during campus and facility design. Cultural background need to be considered closely by designers so that students and staff are provided with friendly work environment. The characteristic and attribute of population of HEI is of moderate importance to program structure and courses contact hours, as shown in left-side of Figure 3.

\subsubsection{Program structure}

The structure of programs to be delivered is usually developed by experts in each field of study. Special attention and consideration should be given to specific local need. The vision and mission statements are carefully observed during the development of the program structure. The program structure stipulates the various courses, modules and units and the number and type of credit hours required to achieve the required level of study. The program structure is of high importance to courses contact hours, as shown in left-side of Figure 3.

\subsubsection{Contact hours}

Contact hours are a product of the educational program. The type and number of contact hours for each course or program of study is used to determine the assignable square meters (ASM) required for various academic and extracurricular facilities around the campus. Occasionally the contact hours are assigned with e-learning component that goes beyond a brick and mortar calculation.

\subsection{Space programming domain}

The proposed sequential phases for this domain are: Contact hours, space standards, academic facilities, academic support facilities, extra-curricular facilities, and amenities. Figure 4 illustrates the structure of the space programming 


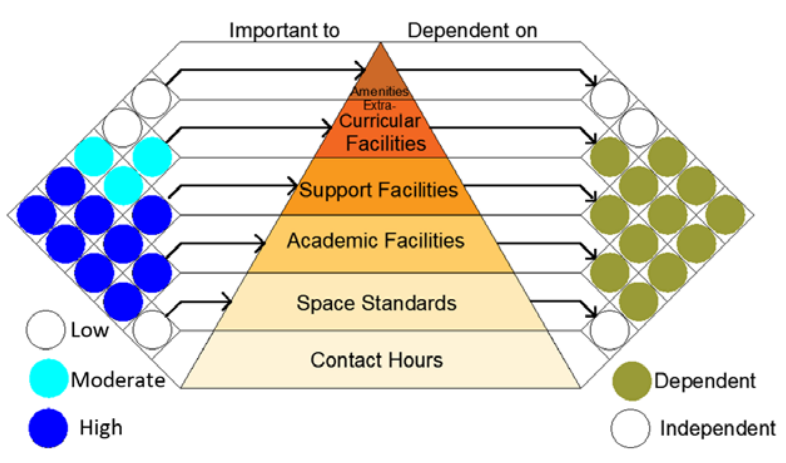

Figure 4. Space program domain

domain and the sequential orders and levels of importance to each phase. Each phase depends on the previous one, except for amenities with both extra-curricular and support facilities, and space standards with contact hours as shown in right-side of the Figure 4.

\subsubsection{Contact hours}

Contact hours are a product of the Educational Program. Application of these numbers to hours of operations, desired classroom sizes, and faculty counts will provide precise estimates of the numbers of classrooms, labs, lecture rooms, seminar rooms, etc. that will be required for basic academic instruction. Contact hours can be used to estimate enrolments and from estimated enrolment numbers, user counts for non-academic support facilities such as dormitories, cafeterias, athletic facilities, and libraries can be estimated. Cultural and local practices will have a major impact on how contact hours are used to estimated enrolments and user counts. In hotter climates, educational facilities may only operate in the cooler morning hours, and other locations evening hours may be the norm. Weekend classes may also be acceptable. The contact hours of the course is of high importance to academic, support, extra-curricular facilities and amenities and is of low importance to space standards, as shown in left-side of Figure 4.

\subsubsection{Space standards}

Space standards establish consistent floor area requirements for each teaching venue - classrooms, lecture rooms, laboratories, and seminar rooms (Jimenez, 2003). Space standards for non-academic facilities, i.e. cafeterias, faculty and administrative offices, athletic facilities can also be established. Room space standards should be developed base on international standards and standards of comparable facilities in the region. A critical issue related to room standards - and one that is most likely to lead to misunderstandings between the educational institution and the Planner/Architect is the definition of gross versus net floor space. Space programs are generally formulated for net floor areas - that is the floor area used for teaching activities, the floor area within the confines of the teaching space. Gross floor area includes additional floor area that is required for non-teaching functions such as circu- lation, mechanical and electrical spaces, toilet rooms, storage closets, etc. The "add-on" to convert net floor are to gross floor area can range from 25 percent to 50 percent or more on top of net floor are to achieve estimates of gross floor area. The "gross-up" factor for educational buildings differs greatly depending on type and use of facility and, generally, where the facility is located. Certain cultures require much more generous circulation space than others and gender separation in certain cultures will have an even further impact on the "gross-up" factor. In the State of Kuwait, for example, a maximum value of $60 \%$ is enforced for the net-to-gross factor, which is equivalent to a gross-up factor of 67\% (Al-Atiqi, 2008). This high grossup factor is attributed to local cultural (gender segregation laws) and environmental (hot outdoors weather) aspects. Space standards are of high importance to academic facilities, support facilities, extra-curricular facilities and amenities as shown in left-side of Figure 4.

\subsubsection{Academic facilities}

Programming for academic facilities is the first order of importance. These facilities include teacher/student facilities - laboratories and classrooms, and student selfteaching facilities - libraries, computer labs, and research facilities. These facilities form the back bone of an educational institution and should receive paramount floor space programming consideration. Although user numbers is the major determinate of floor space needs, methods for teaching and for information delivery will also impact floor space requirements. New concepts for learning environments, i.e., classrooms as "living rooms" and off-site "outof-the-classroom" delivery of instructional materials may reshape thinking regarding rooms sizes and the ultimate need for classrooms in general. In the future, a large number of the student population could be receiving instruction through the use of "smart phones" or tablet PCs with applications specific to the course being taught. The ability to improve instruction by integrating digital technologies across the curriculum is becoming a reality (Gloster II \& Saltzberg, 1996; Hossein, 2002). This technological advance in information technology is positively influencing the availability of online digital resources for teaching and assessments especially those prepared by textbook authors and publishing houses. Furthermore, higher educational institutions are increasingly organizing workshops on latest technology tools to upgrade the skills of their faculty (Young, 2010). The Technical Design Guidelines for private universities in the State of Kuwait (Al-Atiqi, 2008) places great importance to proper IT infrastructure provision that would live up to the modern technological advances and demands on and off-campus. Academic facilities are of high importance to academic support facilities, and of low importance to extra-curricular facilities and amenities, as shown in left-side of Figure 4.

\subsubsection{Academic support facilities}

Academic support facilities can be grouped into two types: 1) those designed primarily for use of students and, 
2) those designed to accommodate activities of the administrative staff and faculty. Student facilities would include dormitories, eating facilities, recreational facilities, health clinics and facilities for the conduct of student activities. Rural campuses will have more of a need for student facilities, urban campus less of a need. Administrative staff and faculty facilities would be nearly identical for both rural and urban campuses - although urban campuses may have more of a size constraint because of the premium on available land for accommodating these facilities. Administrative and faculty facilities consist primarily of offices and office space.

Certain measures can be taken to reduce floor space requirements for support facilities. These may include "hoteling" of offices for faculty, utilizing local unaffiliated facilities for recreational uses, using private off-campus residences for student housing, and located "back-of-thehouse" administrative activities to leased off-campus spaces. All of these measures - with the exception of "hoteling" do not reduce the space requirements for certain support facilities - they just shift the location from on-campus to off-campus with probable cost savings. Academic support facilities are of moderate importance to extra-curricular facilities, and of low importance to amenities, as shown in left-side of Figure 4.

\subsubsection{Extra-curricular facilities}

The facilities are student-focused, to attract potential students and to maintain and enhance the social and physical well being of students (and faculty and staff alike). These facilities include social centers, game rooms, spaces for student activities and meetings, wellness and fitness centers, and all recreational facilities. These facilities are not essential to basic academic functions, but in a competitive world, they are essential to attracting the brightest and best students. Certain studies have shown that there is a direct correlation between students well being - socially and physically - and their academic performances (ElAnsari \& Stock, 2010; Quinn \& Duckworth, 2007). ExtraCurricular facilities are of low importance to amenities, as shown in left-side of Figure 4.

\subsubsection{Amenities}

These facilities are neither support facilities nor facilities for extra-curricular activities. These facilities are mostly convenience facilities that enhance student life and/or free up student time for pursuit of expanded academic opportunities. These facilities might include daycare centers for student mothers, student shuttle systems, on-site laundry, banking, and convenience shopping facilities. Non convenience amenities would include such facilities as art galleries, sculpture gardens, and on-campus movie theatres.

\subsection{Master plan domain}

Master planning is started once the land or plots allocated for the HE institution are decided, and the sequential key processes involved are: Planning regulations and guide-

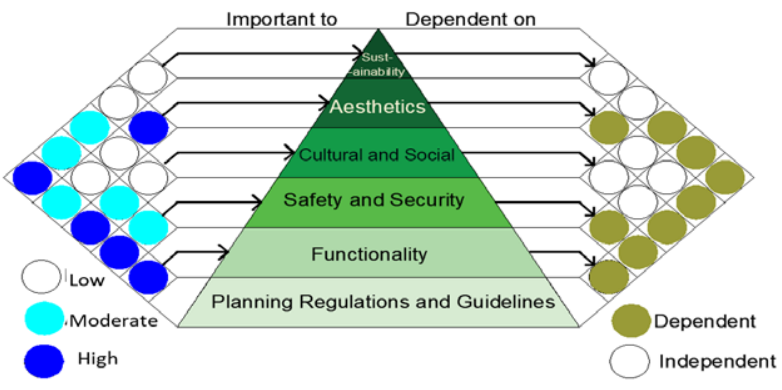

Figure 5. Master plan domain

lines, functionality, safety and security, aesthetics and innovation, cultural/social, and sustainability. Figure 5 illustrates the structure of the Master plan domain and the sequential orders and level of importance to each phase. Each phase depends on the previous one. Exceptions to this phase dependency are sustainability with aesthetics, cultural, and social context; aesthetics with safety and functionality; and cultural and social context with safety and functionality, as shown in right-side of Figure 5.

\subsubsection{Planning regulations and guidelines}

Regulations and guidelines are usually extracted from analyses of regional context and project site, in addition to urban planning regulations, and building codes. Evaluation of such inputs sets the frame for development of campus master plan. Such contextual approach for developing the concept takes into consideration urban characteristics of the large city and narrow site, climatic features, site accessibility, and traffic impact of the project on the surrounding zone. They also establish the structure for evaluating different master plan proposals and/or modifications to existing master plans. Master planning design guidelines focus on the uses of land, pedestrian and vehicular circulation, and the location, size, and form of facilities. More recently guidelines related to sustainability, phasing and flexibility, and life-cycle costs have been added to the traditional set of master planning design guidelines. Without a set of design guidelines master planning efforts would have no logical basis for acceptance and implementation. Planning regulations and guidelines validate master planning decisions. Master planning efforts without design guidelines often result in inefficient use of land, inappropriate locations for buildings, and "locked-in" solutions which leave little room for flexibility and phasing of future facilities. The matrix in Table 1, below, is used to demonstrate typical master planning guidelines.

The planning regulations and guidelines are of high importance to functionality, safety and security, culture and social context, and sustainability, with moderate importance to aesthetics, as shown on left-side of Figure 5.

\subsubsection{Functionality}

Functionality is the basic foundation of master planning. The first priority for an educational institution is to "make things work". Basic spatial issues related to access and location of parking, relationships between buildings, 
Table 1. Matrix showing typical master plan regulations and guidelines

\begin{tabular}{|l|l|}
\hline \multicolumn{1}{|c|}{ Design consideration } & \\
\hline Urban characteristics & The project enhances the sense of urban style and respects the city and neighbourhood characteristics \\
\hline Climatic features & The campus plan shall respond to the climatic features to ensure human comfort and wellbeing \\
\hline Accessibility & $\begin{array}{l}\text { The main entrances and exits shall be decided to ensure easy access and exit to the campus without any } \\
\text { conflict to the public traffic of pedestrian, vehicles, and cycling }\end{array}$ \\
\hline Traffic impact & $\begin{array}{l}\text { The campus car parking capacity shall not contradict the public traffic on the roads of the } \\
\text { neighbourhood }\end{array}$ \\
\hline Utilities and services & $\begin{array}{l}\text { The project shall not overload the existing utilities and services. The master plan of the campus shall } \\
\text { include proper solution to any shortage of utilities due to the project }\end{array}$ \\
\hline Land uses & $\begin{array}{l}\text { Allowable land uses; minimum and/or maximum ground coverage for buildings, landscaping, roadways/ } \\
\text { parking. Prohibited uses }\end{array}$ \\
\hline Pedestrian circulation & Sidewalk dimensioning; requirements for covered walkways. Sidewalk capacities \\
\hline Vehicular circulation & $\begin{array}{l}\text { Parking requirements, loading/servicing requirements, general roadway dimensioning; entrance/exit } \\
\text { locations and numbers. Alternative means of transportation }\end{array}$ \\
\hline Building locations & $\begin{array}{l}\text { Front, side, and rear yard setbacks, maximum ground coverage, minimum distances between buildings. } \\
\text { Setbacks from conservation areas }\end{array}$ \\
\hline Building configurations & Maximum building heights, floor area ratios, and floor-to-floor dimensions \\
\hline Sustainability & $\begin{array}{l}\text { Requirements for USGBC LEED Certification, energy efficiency, use of local materials, prohibitive } \\
\text { materials, reduced water consumption, reduced run-off; reduced heat-islands }\end{array}$ \\
\hline Phasing & An implementation plan - correlated to enrolment and parking requirements \\
\hline Flexibility & Expansion capabilities, change in use \\
\hline Life-cycle costs & Maintenance and operational costs over time related to construction costs \\
\hline
\end{tabular}

and basic provisions for teaching facilities - size and type of facility, are addressed in terms of functionality. At the functionality level of the Master $\mathrm{f}$ little consideration is given to aesthetics, safety and security, social and cultural concerns, and/or sustainability. Current, pragmatic needs are the only consideration - no thought is given to future growth and expansion needs. Functionality is of moderate importance to safety and security, culture and social context, and sustainability, and is of low importance to aesthetics, as shown on left-side of Figure 5.

\subsubsection{Safety and security}

Safety and security have received increased attention over the past decade due to increased terrorism and anti-social activities around the world. With respect to campus planning, safety and security is considered at two levels: 1 ) at the campus-wide level and 2) the individual level - student, faculty, and staff. Campus level security measures are expanding from the traditional security guard on patrol to much more sophisticated, all-encompassing programs that include security patrols video camera surveillance, cardcontrolled access to individual buildings, emergency call stations, and gate checks at the perimeter of the campus. At the level of the individual, security levels are expanding thru photo-identification cards, card access to dormitories and to student rooms, background checks of staff and faculty, and camera surveillance. Implementation of enhanced security and safety measures on campuses, with the help of latest security technologies, has resulted in a measurable decline in security and safety incidents over the past decade. The rising awareness of the importance of improving security levels on campuses is gaining media and scholarly attention (Campus News, 2009; Chylinski, 2010). Safety and security are of moderate importance to sustainability, and low importance to culture and social context and aesthetics, as shown on left-side of Figure 5.

\subsubsection{Cultural and social}

As institutions of higher education become more international and heterogeneous in their student and faculty mix, educational programming, campus planning, and facility design has become much more sensitive to the different customs and cultures of the student mix. Course offerings are being expanded to include courses in multi-cultural and ethnic studies, expanded language offerings, and more gender-focuses studies. Student actives are being expanded to include a wider spectrum of cultural and ethnic opportunities and campus planning and designs are become more sensitive to local customs and traditions. The learning experience from these efforts is one where students learning from each other - one step above the student/ teacher learning experience. Culture and social context are of high importance to aesthetics, and low importance to sustainability, as shown on left-side of Figure 5.

\subsubsection{Aesthetics}

Aesthetics in campus planning will have a positive effect on learning and student well-being. Pleasant surroundings, innovative designs and peaceful spaces tend to encourage and enhance creative and innovative thinking. Buildings and their environs act as a passive stimulus to learning. Attractive, well-defined and well-maintained 
campus grounds and buildings enhance one's image of the education institution and stemming from this - an increase self-image for the student (or faculty and staff). Pride in one's school reinforces pride in one's self. Innovation in campus design and campus planning reinforced institution goals related to forward thinking and acceptance of new technologies. Since higher educational institutions appreciate the importance of aesthetics and proper architectural design, they give some freedom to architects to improve teaching and learning spaces without a direct connection to how or what is being taught and learned in the environment (Wedge \& Kearns, 2005). Aesthetics are of low importance to sustainability, as shown on left-side of Figure 5.

\subsubsection{Sustainability}

Within the context of global warming, concerns about solid waste disposal, resources conservation, increased energy costs, and urban sprawl, issues of sustainability are becoming more and more important with respect to campus planning efforts.

Basic goals for sustainability with respect to campus planning include minimizing disturbances to natural habitats, minimizing building and parking lot foot prints, minimizing disruption to storm water run-off flows, minimizing heat-island affects, encouraging use of non-automobile transportation, reducing water and energy consumption, and maximizing reliance on local materials for construction and non-fossil fuels for energy generation. Sustainability programs incorporated into campus planning proposals will result in long term cost savings for the Institution while contributing to the general overall well-being of the environment.

\subsection{Detailed plan domain}

The detailed plan domain includes: Building design guidelines, functionality, safety and security, aesthetics and innovation, cultural/social, and sustainability. Figure 6 illustrates the structure of the detailed plan domain and the

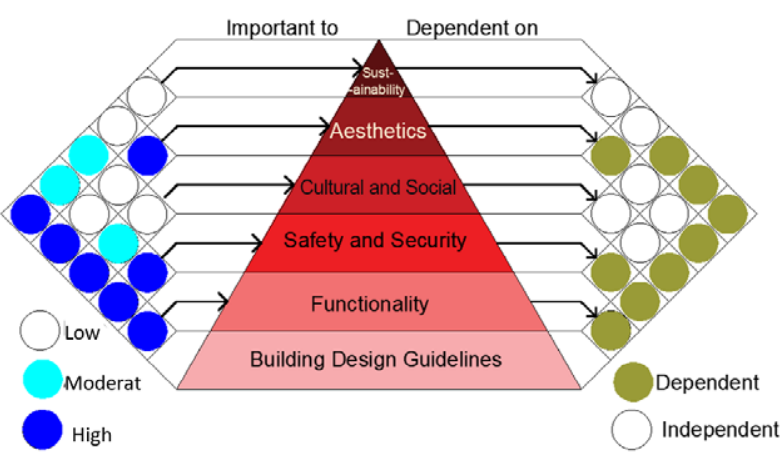

Figure 6. Detailed plan domain

sequential orders and level of importance to each phase. Each phase depends on the previous one, except sustainability with aesthetics and cultural and social context, aesthetics with safety and functionality, and cultural and social context with safety and functionality as shown on right-side of the Figure 6.

\subsubsection{Building design guidelines}

The purpose of design guidelines for building and other campus facilities is to establish the basic frame work for new or renovation design work. That is to say, to establish guidelines related to: 1) building shape and form (height, location, size, and massing), 2) building appearances (exterior cladding materials, colours, and 3) overall building architectural style (traditional, contemporary, and mixed). Design guidelines ensure compatibility and uniformity (with some room for eccentricity) of new and renovated buildings with existing campus buildings and facilities thus providing an overall cohesiveness to the campus appearance. This is important because campuses are developed over a period of decades and in any instances over centuries and a set of a basic design metric will ensure that campuses expand and develop over time in a logical manner. Typical detailed building design guidelines are summarized in the following matrix in Table 2.

Table 2. Matrix showing typical detailed building design guidelines

\begin{tabular}{|l|l|}
\hline \multicolumn{1}{|c|}{ Design consideration } & \multicolumn{1}{c|}{ Guidelines } \\
\hline Land uses & $\begin{array}{l}\text { Allowable land uses; minimum and/or maximum ground coverage for buildings, landscaping, } \\
\text { roadways/parking. Prohibited uses }\end{array}$ \\
\hline Pedestrian circulation & Sidewalk dimensioning; requirements for covered walkways. Sidewalk capacities \\
\hline Vehicular circulation & $\begin{array}{l}\text { Parking requirements, loading/servicing requirements, general roadway dimensioning; entrance/exit } \\
\text { locations and numbers. Alternative means of transportation }\end{array}$ \\
\hline Building locations & $\begin{array}{l}\text { Front, side, and rear yard setbacks, maximum ground coverage, minimum distances between buildings. } \\
\text { Setbacks from conservation areas }\end{array}$ \\
\hline Building configurations & Maximum building heights, floor area ratios, and floor-to-floor dimensions \\
\hline Sustainability & $\begin{array}{l}\text { Requirements for USGBC LEED Certification, energy efficiency, use of local materials, prohibitive } \\
\text { materials, reduced water consumption, reduced run-off; reduced heat-islands }\end{array}$ \\
\hline Phasing & An implementation plan - correlated to enrolment and parking requirements \\
\hline Flexibility & Expansion capabilities, change in use \\
\hline Life-cycle costs & Maintenance and operational costs over time related to construction costs \\
\hline
\end{tabular}


Building design guidelines are of high importance to functionality, safety and security, culture and social context, aesthetics, and sustainability, as shown on left-side of Figure 6.

\subsubsection{Functionality}

Similar to the Master Planning Domain, the first concern in Detailed Design Domain is functionality. Before concept design work begins, functional diagram of activities to be accommodated within a building are drawn up to shown relationships and adjacency requirements between the different activities. This functional diagram is next translated into a set of blocking and stacking diagrams which assign uses to certain floors and locations within the floors. The next step would be to transform the blocking and stacking diagrams into conceptual architectural design work were aesthetics and creative take over. Functionality is of moderate importance to safety and security, culture and social context, and sustainability, and low importance to aesthetics, as shown on left-side of Figure 6.

\subsubsection{Safety and security}

Safety and security concerns related to building design focus on 1) personal safety of users, and 2) building security. Safety for users is generally covered by local, national, and international building and fire code requirements and other government regulations such those put out by the U.S. Occupational Safety and Health Administration (OSHA). These codes and regulations provide for protection against potential fire and environmental (air, water quality, noise) hazards. Building security issues concern controlled access to buildings, monitoring of security and life safety system, and monitoring of maintenance and operational equipment. Safety and security systems protect buildings from potential costly physical and operational losses and ensure personal safety and well-being for users. Safety and security is of moderate importance to sustainability, and low importance to culture and social context and aesthetics, as shown on left-side of Figure 6.

\subsubsection{Cultural and social}

Cultural and social issues related to building design include considerations for gender separation, cultural design practices such as Fueng Sui, and - in some regions - integration or segregation of different social classes and/or different user groups (families, married females and married males, single-males, single females). Subtle differences like the culturally accepted of space between individuals in public venues may have a significant effect on corridor dimensions, toilet room designs, and sizes of teaching spaces. Culture and social context is of high importance to aesthetics, and low importance to sustainability, as shown on left-side of Figure 6.

\subsubsection{Aesthetics}

Aesthetics are what make spaces interesting, lively, and stimulating. High levels of aesthetics speak of creativity and innovation, which in turn contribute to the education experience of users. Attention to developing aesthetics moves a building or space out of the realm of blandness and pure functionality. Students who feel good about their learning spaces will tend to feel good about themselves which carries over to a higher level of pride in their institution. Aesthetics is of low importance to sustainability, as shown on left-side of Figure 6.

\subsubsection{Sustainability}

Sustainability seeks to develop a holistic way of life that has a minimum impact on the environment and its precious and diminishing resources (David, 2003). It aims at striking a balance between economy, community and ecology. Today, sustainability is generally accepted as an important goal of building and facility design, which are responsible for consuming around $50 \%$ of generated energy. Primary objectives of sustainability relate to reduce energy consumption, use of alternative energy sources, re-use of buildings and materials, use of non-toxic and recycled materials, reduced water consumption, individual control of environmental and lighting systems, use of local materials, day lighting, and energy efficiency. Certain of these objectives are applicable to existing buildings as well as to new construction.

\section{Survey of design campus experts}

This survey aims to support the arguments presented above in the literature review and the discussion on the proposed design taxonomy of HEIs campuses. In particular, the considerations aspects that must be adhered to in the phases of the proposed of planning and design taxonomy for HEIs campuses. Therefore, the survey targeted academics who are experts in the design of academic programs and campuses of HEIs. An "M.S. Office" survey form was distributed to relevant experts in the field. The criteria of selecting the experts to be surveyed was their experience in planning and architectural design of campuses for academic institutions with consideration to covering worldwide institutions. Some of the targeted experts were known to the authors through academic collaborations, whilst others were searched in the universities' website with verification of relevant experiences in their resumes. The survey form was circulated to 150 email address in Australia, United Kingdom, United states, Canada, Egypt, and Bahrain. We received 130 completed responses from various universities. Amongst received responses, 92\% confirmed having the design and development of academic programs experience shown in Figure 7. This positive percentage provides confidence in our model and supports the viability of the aspects that need to be adhered to in the educational programming domain of taxonomy model of campus development. The results of the survey further stated that aspects of designing and revising the academic program are university vision, population, program structure, market demand and contact hours. These aspects are sorted and shown in the Figure 8. 
Have you been involved in process of design and development of a program/course?

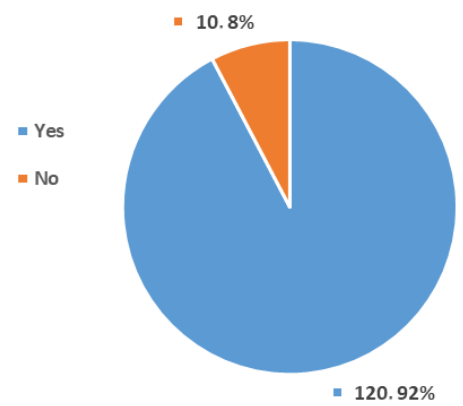

Figure 7. Survey results on program development experience

What are the aspects that should be considered for designing or revising an academic program/course?

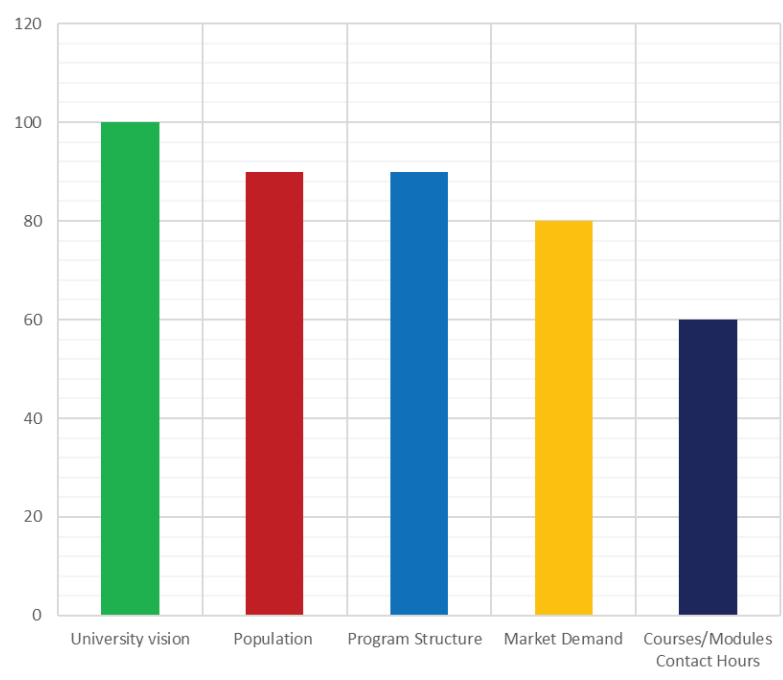

Figure 8. Consideration aspects of academic program development

What are the aspects that should be considered when the university identify the spaces program for the new campus project?

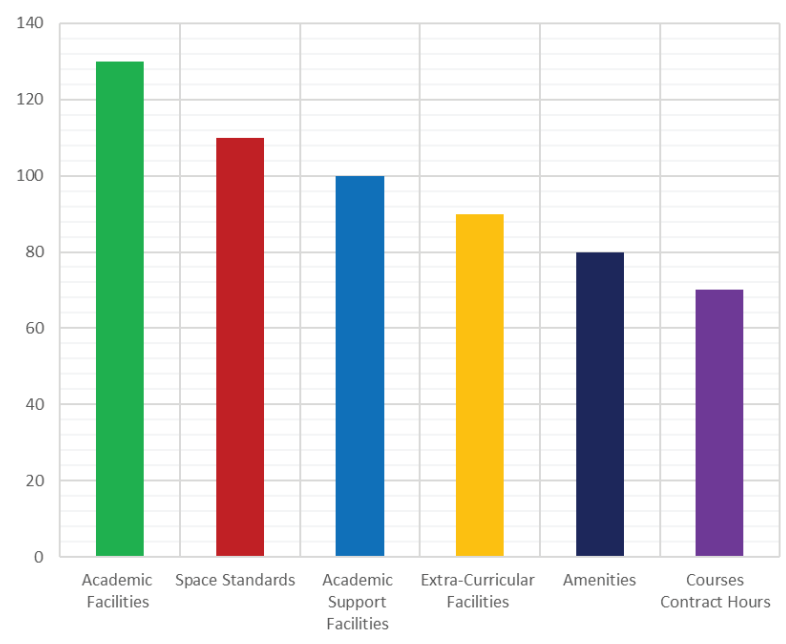

Figure 10. Consideration aspects of space programming of HEIs campuses
Have you been involved in planning and designing a new campus or extension building for your Higher Education Institution?

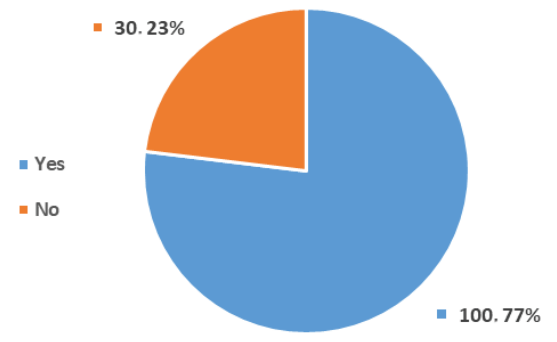

Figure 9. Survey results on campus planning and designing experience

$77 \%$ of the survey results demonstrated direct involvement and experience in planning and designing campus of HEI as shown in Figure 9. This percentage provides further confidence in the survey and supports the validity of the results regarding the aspects that must be considered in the domains of spaces programming, master planning and detailed design of HIEs campuses.

The results from the survey have shown that aspects of campus spaces programming are academic facilitates, space standards, academic support facilities, extra-curricular facilitates, amenities and contact hours. These aspects are sorted and presented in Figure 10 from highest to lowest. They further indicated that the aspects of master planning of HEIs campuses are safety and security, functionality, sustainability, planning regulations, aesthetics and cultural and social. These aspects are sorted and presented in Figure 11. Moreover, the results from the survey stated that the aspects of developing detailed design of HEIs campuses are functionality, safety and security, sustainability, building regulations, cultural and social

What are the aspects that should be considered when the architectural planner develops the master plan for the new campus?

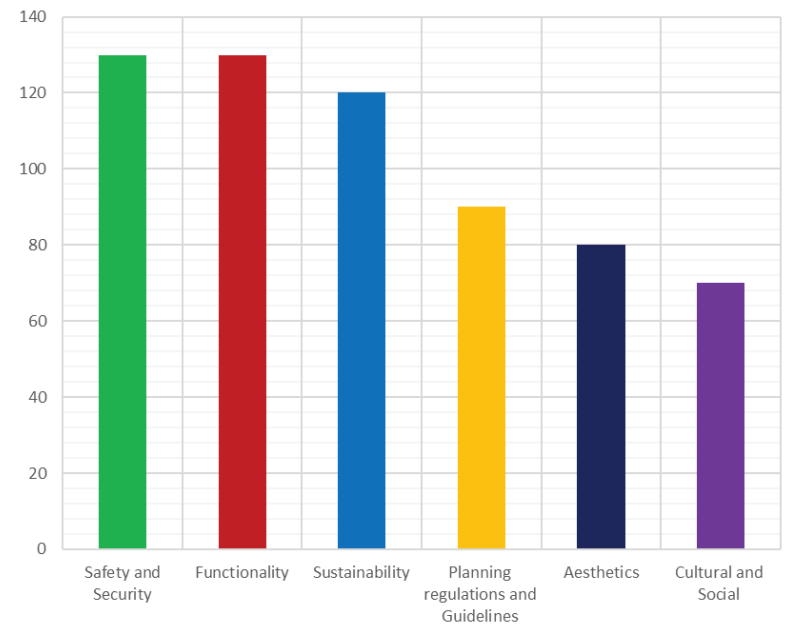

Figure 11. Consideration aspects of master planning of HEIs campuses 
What are aspects should be considered when the architect develops the detailed plan of the new campus?

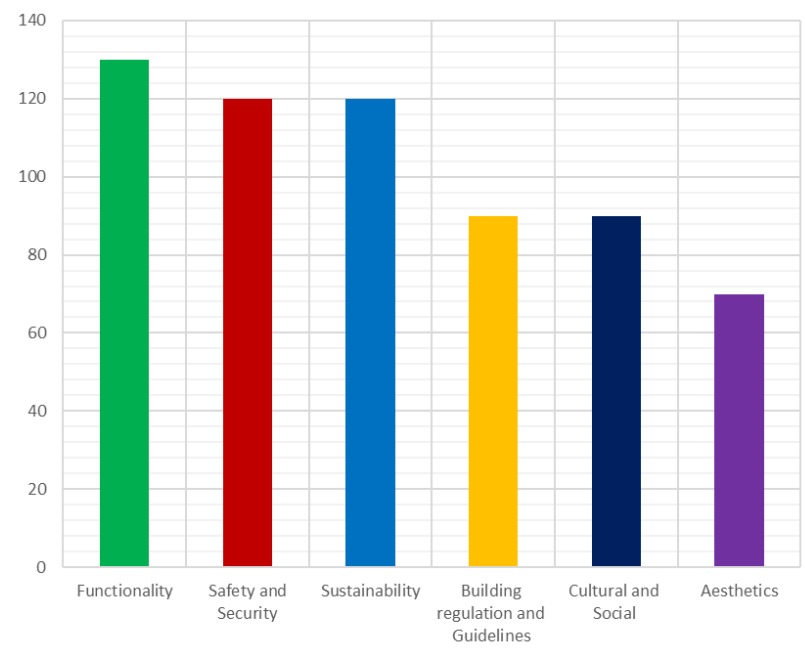

Figure 12. Consideration aspects of detailed design of HEIs campuses

and aesthetics. These aspects are sorted and presented in Figure 12.

For each survey question there was a field to allow for adding additional considerations. A number of respondents added the need for some specific facilities for accreditations, which are already considered in the proposed taxonomy within the academic facilities, academic support facilities, extra-curricular facilities, and amenities. Therefore, such responses were not included in the charts above. The findings of the survey indicate that the proposed design taxonomy of campuses is considerably important and could present a very useful guide to HEI developers for planning and designing the universities campuses.

\section{Case study: campus of Kingdom University}

Kingdom University (KU) is a private higher education institution situated in Kingdom of Bahrain. The campus of KU has been developed to be executed in four growths phases. On 2004, KU started its higher education services through the offering programs of bachelor and Masters' degrees in a rental campus with total floor areas are no more than 4.500 Sq. m. It moved its campus, in 2014, to its privately owned buildings with a total floor area of 4.750 Sq. m. This has been extended, in 2020, to reach 24.000 Sq. m. Furthermore, KU has a future plan to establish a new campus with a total floor area 138.000 Sq. m. Table 3 shows the four phases of the campus development and considerations that were taken.

Phase I (2002-2013): The campus was rented on two floors in an ancient building located in Zinj district in Manama. It included lecture rooms, computer labs, staff offices and canteen. The university was not involved in the original design process of the building which was rented. Therefore, none of the planning and designing principles discussed in this paper were considered. Due to the need for a better design of the educational facilities', student enrolments had been influenced adversely with a sizeable reduction from 2.142 in AY 2008-2009 to 1.288 in AY 20112012. Moreover, the regulators provided advice to improve the quality and adequacy of learning environment.

Phase II (2014-2019): KU revised its strategic plan, policies and procedures to adhere Bahrain quality standards for second cycle of Institutional and academic

Table 3. Planning and designing considerations in KU campus through different phases

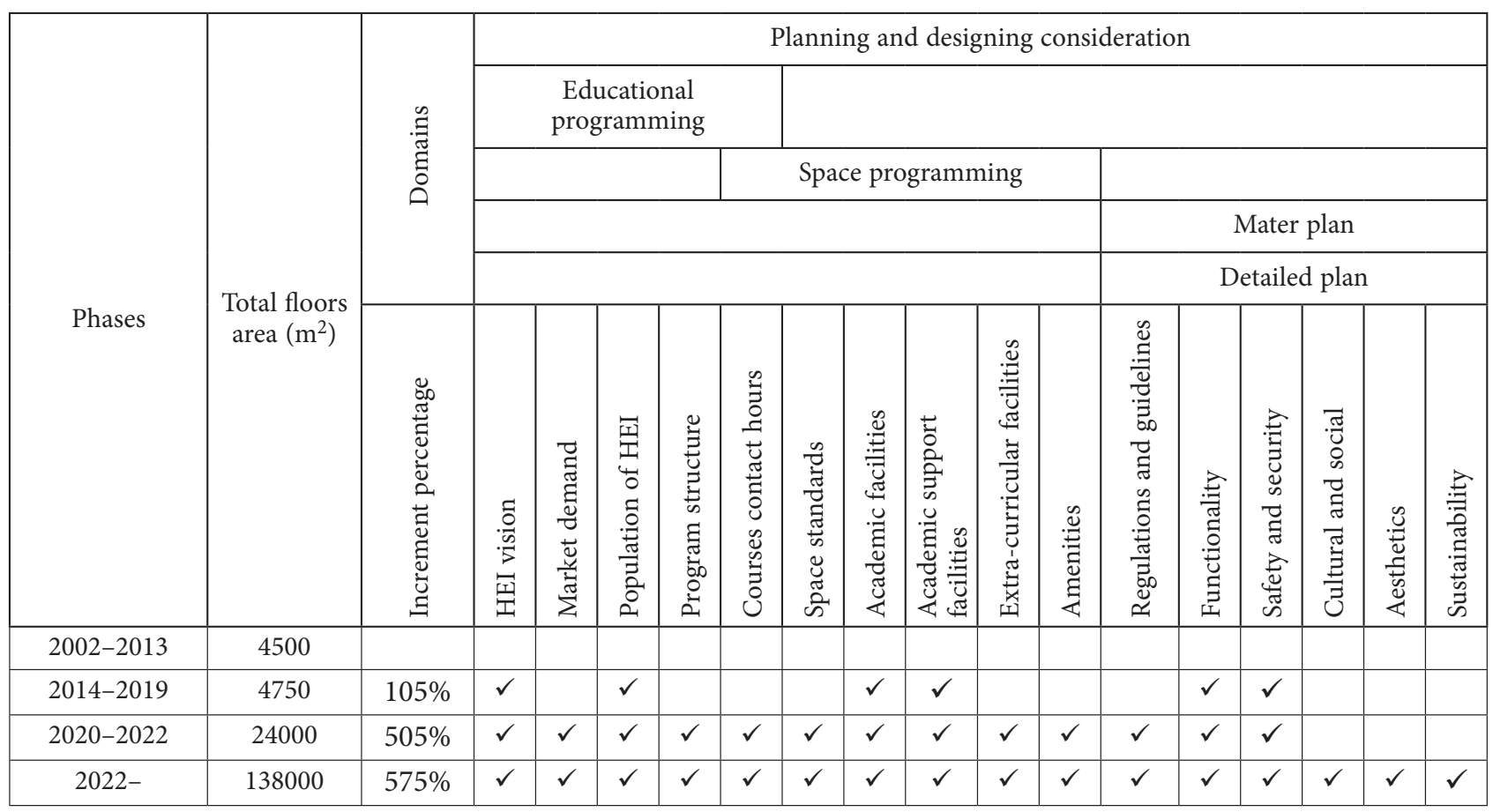


programs reviews. Therefore, the university started to develop the academic programs including improvement of the facilities in the new campus that consisted of two adjacent connected seven-floors office buildings. KU redesigned the interior spaces taking into consideration the vision and mission of the university through allocating adequate spaces for research rooms in the library, offices for community engagement unit, and mood court for law professional practices. University life at KU was taken into account through the allocation of spaces for a clinic, students council, waiting areas, lounge rooms, and self-study areas. Academic facilities were given ample design consideration such as library with adequate resources, more design studios, workshops, and labs for architectural design. Support facilities were also given design attention such as IT server room, bookshop and additional administrative offices. Furthermore, safety facilities and security services were put in place with multiple emergency exits, fire alarms, firefighting systems, and monitoring systems. Compared to the campus of phase I, the functional requirements of the spaces have been much adequately addressed. The students' enrolments increased during phase II of the campus development. It has increased from 1.528 in AY 2012-2013 to 2.113 students in AY 2017-2018. In 2014-2015, four programs were reviewed by BQA and obtained full confidence whilst two programs obtained limited confidence. In 2019, The university achieved institutional accreditations with both HEC and BQA. This achievement was largely attributed to improvements in vision, population satisfaction surveys, adequacy of facilities and efficient building functionality and in particular taking into consideration the campus development which its actual operation in phase III.

Phase III 2020-2022 (Current campus): The educational programming process currently operates through all proposed taxonomy phases. Kingdom University continues its revisions of the existing 7 undergraduate programs. Revising the existing and developing the new programs are carried out to achieve the mission and mis- sion of the university. Newly revised and developed programs were based on Bahrain and GCC market needs, stakeholders survey. Moreover, the academic programs are designed with its structure coherent with the $\mathrm{Na}$ tional Qualification Framework (NQF) level for courses according to the placement of program degree. The contact hours of the programs were revised according to the standard of student workload that was counted based on the notion of hours for each course. This further revision and development in the programmes of KU entailed a new campus growth through an extended seven-floor academic building, multi-storey parking structure, and ground floor workshops and labs. The spaces of the extensions have been programmed based on the contact hours of the 7 existing programs. Tables 4, 5 and 6 present the use of contact hours as a main factor for spaces programming of academic and academic support facilities. Extra-curricular facilities were planned according to the total capacity of the campus and the national Higher Education Council (HEC) standards as shown in Table 7. All facilities of the extension building were planned and designed following the standards and requirements of HEC, Bahrain Building regulations related to land use, building heights, building setback, safety and civil defence requirements. Cultural and social context were not considered in campus planning process. This affected the community services where no facilities were available to the surrounding community such as playgrounds. The absence of aesthetics in the campus planning and design affected marketing of the university adversely since there were no iconic and well-designed building façades that created a visible landmark. The lack of considerations for sustainability inflicted high costs on the building operations including electricity and water bills in addition to maintenance. Enrolment during AY 2019-2020 was the highest since the establishment of the university. This result should not come as a surprise taking into account most of planning considerations within the proposed planning taxonomy model for the campus.

Table 4. Contact hour-based calculation of required capacity of academic facilities

\begin{tabular}{|c|c|c|c|c|c|c|c|}
\hline Academic programs & TCHP & NSP & ACHS & $\mathrm{NCHD}$ & NCSP & TNS & $R C A F$ \\
\hline B.Sc. in Architecture Engineering & 237 & 10 & 24 & 5 & 2 & \multirow[t]{2}{*}{650} & \multirow[t]{2}{*}{325} \\
\hline B.Sc. in Interior Design & 196 & 8 & 24.5 & 5 & 2 & & \\
\hline B.Sc. in Business Management & \multirow[t]{3}{*}{129} & \multirow[t]{3}{*}{8} & \multirow[t]{3}{*}{16} & \multirow[t]{3}{*}{3} & \multirow[t]{3}{*}{3} & \multirow[t]{3}{*}{1275} & \multirow[t]{3}{*}{425} \\
\hline B.Sc. in Finance and Accounting & & & & & & & \\
\hline B.Sc. in Finance and Banking & & & & & & & \\
\hline B.Sc. in Law & 138 & 8 & 17 & 3.5 & 2.8 & 1350 & 482 \\
\hline Total & & & & & & 3275 & 1232 \\
\hline
\end{tabular}

Notes: $[$ TCHP $]$ is Total of contact hours of the program = Allocated hours for lectures, studios, and labs; $[$ NSP $]$ is No of semesters per program; $[A C H S]$

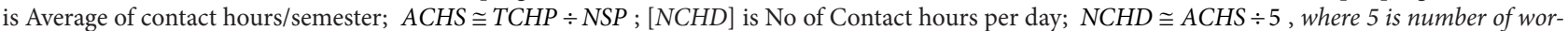

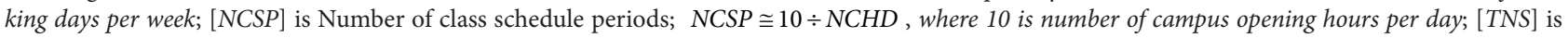
Target Number of Students; $[R C A F]$ is Required Capacity of Academic facilities; $R C A F \cong T B S \div N C S P$, then the required capacity is distributed to be compatible with HEC standards of academic facilities, where $1.7 \mathrm{~m}^{2} /$ student in the lecture room, $2.6 \mathrm{~m}^{2} / \mathrm{student}$ in studio and classroom, $6 \mathrm{~m} / \mathrm{student}$ in computer lab, and $9 \mathrm{~m}^{2} /$ student in workshops and laboratory (Resolution No. (4)/2007 for regulations of HEIs buildings, 2007). 
Table 5. Academic facility planning according to HEC standards

\begin{tabular}{|c|c|c|c|c|c|c|c|c|c|c|c|c|c|}
\hline \multirow[b]{2}{*}{ Academic programs } & \multirow[b]{2}{*}{$R C A F$} & \multicolumn{3}{|c|}{ Studios } & \multicolumn{3}{|c|}{ Classrooms } & \multicolumn{3}{|c|}{ Workshops } & \multicolumn{3}{|c|}{ Computer labs } \\
\hline & & ¿̇ & 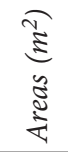 & 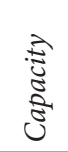 & $\dot{z}$ & 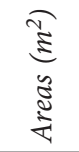 & $\begin{array}{l}\text { 壳 } \\
\text { हे } \\
\text { डे }\end{array}$ & 之ं & 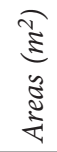 & $\begin{array}{l}\text { त्ञ } \\
\text { है } \\
\text { है }\end{array}$ & $z$ & 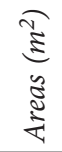 & 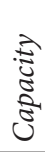 \\
\hline B.Sc. in Architecture Engineering & \multirow[t]{2}{*}{325} & \multirow[t]{2}{*}{12} & \multirow[t]{2}{*}{213} & \multirow[t]{2}{*}{230} & \multirow[t]{2}{*}{1} & \multirow[t]{2}{*}{34} & \multirow[t]{2}{*}{20} & \multirow[t]{2}{*}{2} & \multirow[t]{2}{*}{360} & \multirow[t]{2}{*}{40} & \multirow[t]{2}{*}{2} & \multirow[t]{2}{*}{215} & \multirow[t]{2}{*}{35} \\
\hline B.Sc. in Interior Design & & & & & & & & & & & & & \\
\hline B.Sc. in Business Management & \multirow[t]{3}{*}{425} & \multirow[t]{3}{*}{-} & \multirow[t]{3}{*}{-} & \multirow[t]{3}{*}{-} & \multirow[t]{3}{*}{12} & \multirow[t]{3}{*}{708} & \multirow[t]{3}{*}{409} & \multirow[t]{3}{*}{-} & \multirow[t]{3}{*}{-} & \multirow[t]{3}{*}{-} & \multirow[t]{3}{*}{1} & \multirow[t]{3}{*}{100} & \multirow[t]{3}{*}{16} \\
\hline B.Sc. in Finance and Accounting & & & & & & & & & & & & & \\
\hline B.Sc. in Finance and Banking & & & & & & & & & & & & & \\
\hline B.Sc. in Law & 482 & 1 & 100 & 38 & 16 & 768 & 444 & & & & & & \\
\hline $\begin{array}{l}\text { Total number of academic spaces } \\
\text { Total capacity (student) } \\
\text { Total areas }\left(\mathrm{m}^{2}\right)\end{array}$ & $\begin{array}{c}47 \\
1232 \\
2498\end{array}$ & 13 & 313 & 268 & 29 & 1510 & 873 & 2 & 360 & 40 & 3 & 315 & 51 \\
\hline
\end{tabular}

Table 6. Academic support facilities planning

\begin{tabular}{|l|c|c|c|c|c|}
\hline \multicolumn{1}{|c|}{ Facilities } & Number of users & No. of rooms/zones & Area $\left(\mathrm{m}^{2}\right)$ & Area/1 user $\left(\mathrm{m}^{2}\right)$ & HEC standards \\
\hline Offices for staff & 84 & 56 & 1656 & 19.7 & $9 \mathrm{~m}^{2}$ \\
\hline Library & 1232 & 1 & 888 & 0.72 & $0.7 \mathrm{~m}^{2}$ \\
\hline Cafeteria/rest areas & 1232 & 2 & 200 & 1.01 & $1 \mathrm{~m}^{2}$ \\
\hline Waiting area & 1232 & 1 & 154 & 3.5 & 0.16 \\
\hline Seminar room & 44 & 1 & 12,000 & 38 & $\begin{array}{c}1 \mathrm{plot} / 5 \mathrm{~m} \text { students } \\
1 \mathrm{plot} / \mathrm{faculty} \\
1 \mathrm{plot} / 2 \mathrm{admin} \text { staff }\end{array}$ \\
\hline Car parking & $\begin{array}{c}1232 \text { students } \\
46 \text { faculty members } \\
42 \text { admin staff }\end{array}$ & $\begin{array}{c}246 \text { plots } \\
46 \text { plots } \\
21 \text { plots }\end{array}$ & & & \\
\hline
\end{tabular}

Note: * (Resolution No. (4)/2007 for regulations of HEIs buildings, 2007).

Table 7. Extra-curricular facilities planning

\begin{tabular}{|l|c|c|c|c|}
\hline \multicolumn{1}{|c|}{ Facilities } & Number of users & No. of rooms/zones & Area $\left(\mathrm{m}^{2}\right)$ & HEC standards \\
\hline Entrepreneur and incubators center & 40 & 1 & 228 & - \\
\hline Sport hall & 1232 & 1 & 1200 & $1500-2000 \mathrm{~m}^{2 * \star}$ \\
\hline Multipurpose room & 500 & 1 & 914 & 1 seat $/ 4$ students $^{\star}$ \\
\hline
\end{tabular}

Notes: ${ }^{*}$ (Resolution No. (4)/2007 for regulations of HEIs buildings, 2007); ${ }^{* *}$ (Resolution No. (1127)/2017 for regulations of Sport facilites in HEIs, 2017).

Phase IV 2022 - (Future Campus Project): a 48.000 Sq. m of land located in Hamad Town is granted to Kingdom University for developing its new campus. The authors were part of the campus planning team, developing the proposed taxonomy is performed prior to developing the campus for this phase. Although earlier phases did not apply the proposed taxonomy, an explanation was applied retrospectively for the phases I-III. The master plan of the campus has been developed according to all of the taxonomy phases of developing the HEI campuses proposed in this paper as described below.

The university vision: KU requested the consultants of the project to develop the design concept taking into consideration the KU vision through providing quality of learning environment that motivates learning, research, innovation, and community engagement that contributes to economic development nationally and regionally. Therefore, the campus consisted of various of facilities that were essential to achieve this vision. This included a central library containing a research centre with an inspirational reading environment, a residential dorm for international female students, academic buildings for each college, a monumental administrative building, and an iconic sports facility. Since the university is involved in green architectural engineering and sustainable energy, the president of $\mathrm{KU}$ made sure the master plan reflected this research interest on the campus design. 
Table 8. Required academic programs and administrative offices

\begin{tabular}{|l|c|c|}
\hline \multicolumn{1}{|c|}{ Academic program } & $\begin{array}{c}\text { Target } \\
\text { students }\end{array}$ & $\begin{array}{c}\text { No. of } \\
\text { Faculty }^{*}\end{array}$ \\
\hline B.Sc. Finance and Accounting & 250 & 10 \\
\hline B.Sc. Finance and Banking & 250 & 10 \\
\hline B.Sc. Business Management & 250 & 10 \\
\hline MBA & 60 & 4 \\
\hline PhD management & 10 & 3 \\
\hline B.Sc. Architectural Engineering & 300 & 12 \\
\hline MSc. Sustainable Arch & 45 & 3 \\
\hline B.Sc. Interior Design & 180 & 8 \\
\hline B.Sc. Construction and Management & 250 & 10 \\
\hline MSc. Construction Enginering & 45 & 3 \\
\hline B.Sc. Chemical Engineering & 100 & 4 \\
\hline BA of Law & 550 & 16 \\
\hline MA of Law & 30 & 2 \\
\hline BA of Political Sciences & 250 & 8 \\
\hline BA in Mass Communication & 250 & 8 \\
\hline B.Sc. of Computer Sciences & 150 & 6 \\
\hline
\end{tabular}

\begin{tabular}{|l|l|}
\hline \multicolumn{1}{|c|}{ Administrative department } & No. of staff \\
\hline President office & 3 \\
\hline Vice president office & 2 \\
\hline AQAQ & 4 \\
\hline Strategic and Governance Unit & 2 \\
\hline Marketing, and Public relations & 3 \\
\hline Admission and registration & 4 \\
\hline ICT & 4 \\
\hline Financial Resources & 3 \\
\hline HR & 3 \\
\hline Purchasing and Services & 3 \\
\hline Students affairs & 3 \\
\hline Community Engagement Unit & 2 \\
\hline Staff development office & 1 \\
\hline Internship and Career guidance & 2 \\
\hline Clinic & 1 \\
\hline
\end{tabular}

Note: ${ }^{*}$ Numbers are determined according to HEC regulations (Resolution No. (2)/2007 for admin and academic affaires of HEIs, 2007).

Market demand: KU top management contributed the design brief of the campus with start of conducting market demands to the different professions through conducting surveys, responding to Bahrain 2030 economic vision and addressing job market demand in Bahrain and the gulf region. Accordingly, the required academic programs and administrative offices are listed in Table 8.

Population of Kingdom University: A detailed knowledge of the population of kingdom University was provided to the consultant architect of the project including the population numbers, job designations, and positions as shown in Table 8. The designer was also allowed to interview the KU stakeholders which are the end users of the campus to define their needs in the workplace and facilities.

Program structure, contact hours, space standards and academic facilities: The study plan and teaching strategy of each academic program has been analysed to determine the required types and capacity of academic facilities according to HEC standards (Resolution No. (4)/2007 for regulations of HEIs buildings, 2007). Lecturing teaching strategy for general science within each college required lecture halls, computer-based learning strategy required computer labs, and design studio-based learning required drawing studios. To ensure optimal utilization of the academic facilities, each type and capacity of those facilities determined to accommodate a percentage of students equal to the same percentage of the relative courses according to the average week study loads. The proposed academic facilities are shown in Table 9.

Academic support facilities: The primary study of the campus planning was presented with the idea of develop- ing a master plan with two basement floors distributed over the entire site for car parking use of the 7 separate buildings. One parking arrangement for each college, administrative building, services building, central library and female dorm. Moreover, all required academic support facilities were distributed amongst the four colleges buildings for administrative use, whilst public use was only allowed in the central buildings of library, administrative, and services buildings. Tables 10 and 11 show the space program of the academic support facilities in the colleges buildings and library building respectively. In addition to the cafeterias located in each college building, a central restaurant with capacity of 375 persons is planned in the services building to serve all the university peoples including students and staff. Admirative workplaces with capacity of 40 admin staff are planned in a separate building including offices rooms, meeting rooms, and rest rooms.

Extra-curricular facilities: As part of the mission of $\mathrm{KU}$ to enhance interaction with the society and encourage extra-curricular activities, the new campus contained art, charity, theater, and alumni clubs with capacity of 300 person each in addition to a multipurpose hall with capacity of 750 persons. Those facilities were placed in the zone specified for the services in the buildings. Sport zone including multigame playgrounds, gym and services were also programmed according to HEC standards with total area of 1850 Sq. m.

Amenities: A residential dorm specific for female students with capacity of 150 students is included in the campus developments to cater for regional and international new recruits. 
Table 9. Proposed space program of academic facilities

\begin{tabular}{|c|c|c|c|c|c|c|c|c|c|c|c|c|c|c|c|c|c|c|c|c|c|c|c|c|c|}
\hline \multirow[b]{2}{*}{ Academic programs } & \multirow[b]{2}{*}{ 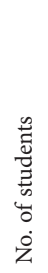 } & \multicolumn{4}{|c|}{ Lecture halls } & \multicolumn{4}{|c|}{ Classrooms } & \multicolumn{4}{|c|}{ Seminar rooms } & \multicolumn{4}{|c|}{ Computer labs } & \multicolumn{4}{|c|}{ Studios } & \multicolumn{4}{|c|}{ Workshops } \\
\hline & & 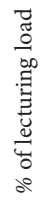 & 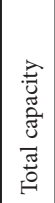 & 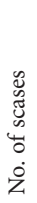 & 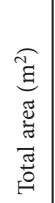 & 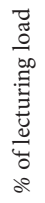 & 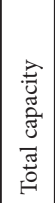 & 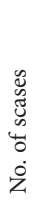 & 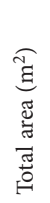 & 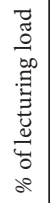 & 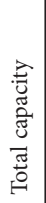 & 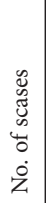 & 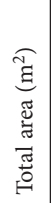 & 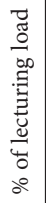 & 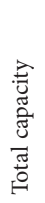 & 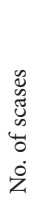 & 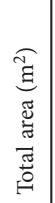 & 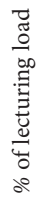 & 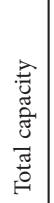 & 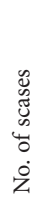 & 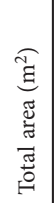 & 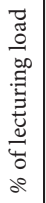 & 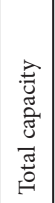 & 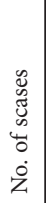 & 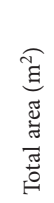 \\
\hline BA Finance and Accounting & 250 & 60 & 150 & 1 & 255 & 35 & 88 & 3 & 228 & 0 & 0 & 0 & 0 & 5 & 13 & 1 & 75 & 0 & 0 & 0 & 0 & 0 & 0 & 0 & 0 \\
\hline BA Finance and Banking & 250 & 60 & 150 & 1 & 255 & 35 & 88 & 3 & 228 & 0 & 0 & 0 & 0 & 5 & 13 & 1 & 75 & 0 & 0 & 0 & 0 & 0 & 0 & 0 & 0 \\
\hline BA Business Management & 250 & 60 & 150 & 1 & 255 & 35 & 88 & 3 & 228 & 0 & 0 & 0 & 0 & 5 & 13 & 1 & 75 & 0 & 0 & 0 & 0 & 0 & 0 & 0 & 0 \\
\hline MBA & 60 & 0 & 0 & 0 & 0 & 0 & 0 & 3 & 0 & 50 & 30 & 3 & 105 & 50 & 30 & 2 & 180 & 0 & 0 & 0 & 0 & 0 & 0 & 0 & 0 \\
\hline Ph.D. Management & 10 & 0 & 0 & 0 & 0 & 0 & 0 & 3 & 0 & 100 & 10 & 1 & 35 & 0 & 0 & 0 & 0 & 0 & 0 & 0 & 0 & 0 & 0 & 0 & 0 \\
\hline Total (College of Business) & 820 & & 450 & 3 & 765 & & 263 & 15 & 683 & & 40 & 4 & 140 & & 68 & 5 & 405 & & 0 & 0 & 0 & & 0 & 0 & 0 \\
\hline B.Sc. Architectural Engineering & 300 & 21 & 63 & \multirow{6}{*}{3} & \multirow{6}{*}{340} & 25 & 75 & 3 & 195 & 0 & 0 & 0 & 0 & 15 & 45 & 3 & 270 & 30 & 90 & 6 & 315 & 9 & 27 & 2 & 243 \\
\hline B.Sc. Interior Design & 180 & 21 & 38 & & & 28 & 50 & 2 & 130 & 0 & 0 & 0 & 0 & 15 & 27 & 2 & 162 & 30 & 54 & 6 & 189 & 6 & 11 & 1 & 97 \\
\hline B.Sc. Const. and Management & 250 & 21 & 53 & & & 20 & 50 & 2 & 130 & 0 & 0 & 0 & 0 & 5 & 13 & \multirow{2}{*}{1} & 75 & 0 & 0 & 0 & 0 & 54 & 135 & 7 & 1215 \\
\hline B.Sc. Chemical Engineering & 100 & 20 & 20 & & & 25 & 25 & 1 & 65 & 0 & 0 & 0 & 0 & 5 & 5 & & 30 & 0 & 0 & 0 & 0 & 50 & 50 & 2 & 450 \\
\hline MSc. Construction Eng. & 45 & 30 & 14 & & & 0 & 0 & 0 & 0 & 50 & 23 & 2 & 79 & 0 & 0 & 0 & 0 & 0 & 0 & 0 & 0 & 20 & 9 & 1 & 81 \\
\hline MSc. Sustainable Arch & 45 & 30 & 14 & & & 0 & 0 & 0 & 0 & 50 & 23 & 2 & 79 & 0 & 0 & 0 & 0 & 0 & 0 & 0 & 0 & 20 & 9 & 1 & 81 \\
\hline Total (College of Engireering) & 920 & & 200 & 3 & 340 & & 200 & 8 & 520 & & 45 & 4 & 158 & & 90 & 6 & 537 & & 144 & 12 & 504 & & 241 & 14 & 2167 \\
\hline BA of Law & 550 & 50 & 275 & 2 & 468 & 40 & 220 & 8 & 572 & 0 & 0 & 0 & 0 & 5 & 28 & 2 & 165 & 5 & 28 & 1 & 96 & 0 & 0 & 0 & 0 \\
\hline MA of Law & 30 & 0 & 0 & 0 & 0 & 0 & 0 & 0 & 0 & 100 & 30 & 2 & 105 & 0 & 0 & 0 & 0 & 0 & 0 & 0 & 0 & 0 & 0 & 0 & 0 \\
\hline BA of Political Sciences & 250 & 50 & 125 & 1 & 213 & 33 & 83 & 3 & 215 & 12 & 30 & 2 & 105 & 5 & 13 & 1 & 75 & 0 & 0 & 0 & 0 & 0 & 0 & 0 & 0 \\
\hline Total (College of Law) & 830 & & 400 & 3 & 680 & & 303 & 11 & 787 & & 60 & 4 & 210 & & 40 & 3 & 240 & & 28 & 1 & 96 & & 0 & 0 & 0 \\
\hline BA in Mass Communication & 250 & 30 & 75 & 1 & 128 & 50 & 125 & 4 & 325 & 0 & 0 & 0 & 0 & 10 & 25 & 2 & 150 & 10 & 25 & 2 & 88 & 0 & 0 & 0 & 0 \\
\hline B.Sc. of Computer Sciences & 150 & 30 & 45 & 1 & 77 & 50 & 75 & 2 & 195 & 0 & 0 & 0 & 0 & 10 & 15 & 1 & 90 & 10 & 15 & 2 & 53 & 0 & 0 & 0 & 0 \\
\hline Total (College of Media) & 400 & & 120 & 2 & 204 & & 200 & 6 & 520 & & 0 & 0 & 0 & & 40 & 3 & 240 & & 40 & 4 & 140 & & 0 & 0 & 0 \\
\hline
\end{tabular}

Table 10. Proposed space program of academic support facilities in the colleges

\begin{tabular}{|c|c|c|c|c|c|c|c|c|c|c|c|c|c|c|c|c|c|}
\hline \multirow[b]{2}{*}{ Spaces } & \multirow[b]{2}{*}{ HEC regulation } & \multicolumn{4}{|c|}{ College of Business } & \multicolumn{4}{|c|}{ College of Engineering } & \multicolumn{4}{|c|}{ College of Law } & \multicolumn{4}{|c|}{ College of Media } \\
\hline & & 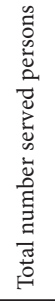 & $\begin{array}{l}\bar{\nu} \\
\text { है } \\
\text { है }\end{array}$ & 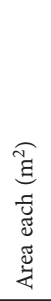 & 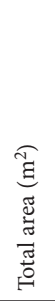 & 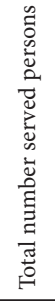 & $\begin{array}{l}\overrightarrow{\mathrm{D}} \\
\text { E } \\
\text { Z }\end{array}$ & 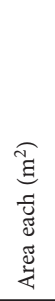 & 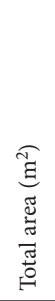 & 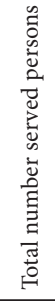 & $\begin{array}{l}\dot{\Xi} \\
\text { है } \\
\text { ż }\end{array}$ & 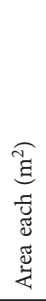 & 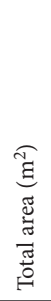 & 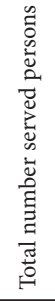 & $\begin{array}{l}\vec{\Delta} \\
\text { 志 } \\
\text { Z }\end{array}$ & 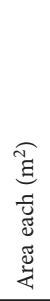 & 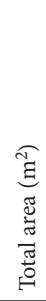 \\
\hline $\begin{array}{l}\text { Cafeteria/Restaurant/ } \\
\text { Rest rooms }\end{array}$ & $\begin{array}{c}4 \mathrm{~m}^{2} / \text { student for } 25 \% \text { of total } \\
\text { number students }\end{array}$ & 103 & 4 & 103 & 412 & 115 & 4 & 115 & 460 & 104 & 4 & 104 & 416 & 50 & 2 & 100 & 200 \\
\hline Restrooms & - & - & 3 & 15 & 45 & 920 & 4 & 15 & 60 & 830 & 4 & 15 & 60 & 400 & 4 & 15 & 60 \\
\hline Female prayer room & - & 427 & 1 & 50 & 50 & 460 & 1 & 50 & 50 & 415 & 1 & 50 & 50 & 200 & 1 & 50 & 50 \\
\hline Male prayer room & - & 427 & 1 & 50 & 50 & 460 & 1 & 50 & 50 & 415 & 1 & 50 & 50 & 200 & 1 & 50 & 50 \\
\hline Printing/copy centre & - & 820 & 2 & 14 & 28 & 920 & 2 & 14 & 28 & 830 & 2 & 14 & 28 & 400 & 2 & 14 & 28 \\
\hline Archiving and storage & - & - & 4 & 70 & 280 & - & 4 & 70 & 280 & - & 4 & 70 & 280 & - & 2 & 70 & 140 \\
\hline Faculty offices & $9 \mathrm{~m}^{2} /$ faculty member & 820 & 35 & 9 & 315 & 920 & 40 & 9 & 360 & 26 & 26 & 9 & 234 & 14 & 14 & 9 & 126 \\
\hline Meeting rooms & - & 35 & 3 & 14 & 42 & 40 & 4 & 20 & 80 & 26 & 3 & 20 & 60 & 14 & 2 & 220 & 40 \\
\hline Staff pantry & - & & & & & 40 & 4 & 10 & 40 & 26 & 3 & 10 & 30 & 14 & 2 & 10 & 20 \\
\hline Secretary & - & 40 & 5 & 9 & 45 & 40 & 5 & 9 & 45 & 26 & 3 & 9 & 27 & 14 & 3 & 9 & 27 \\
\hline Exhibition & - & & & & & 920 & 2 & 250 & 500 & & & & & & & & \\
\hline Staff toilets & $\begin{array}{l}1 \mathrm{WC} / 20 \text { faculty } 50 \% \text { for } \\
\text { each gender }\end{array}$ & 35 & 8 & 8 & 32 & 40 & 8 & 4 & 32 & 26 & 8 & 4 & 32 & 14 & 8 & 4 & 32 \\
\hline Male students toilets & $1 \mathrm{WC} / 20$ students & 420 & 21 & 4 & 84 & 460 & 23 & 4 & 92 & 415 & 21 & 4 & 84 & 200 & 10 & 4 & 40 \\
\hline Female students toilets & $1 \mathrm{WC} / 20$ students & 420 & 21 & 4 & 84 & 460 & 23 & 4 & 92 & 415 & 21 & 4 & 84 & 200 & 10 & 4 & 40 \\
\hline
\end{tabular}


Table 11. Proposed space program of the central library

\begin{tabular}{|c|c|c|c|c|c|}
\hline Spaces & HEC regulation & Number & $\begin{array}{l}\text { No. served } \\
\text { persons }\end{array}$ & $\begin{array}{l}\text { Area each } \\
\left(\mathrm{m}^{2}\right)\end{array}$ & $\begin{array}{l}\text { Total area } \\
\left(\mathrm{m}^{2}\right)\end{array}$ \\
\hline Reading area & $\begin{array}{c}0.7 \mathrm{~m}^{2} / 1 \text { student for } 10 \% \text { of total } \\
\text { number of students }\end{array}$ & 1 in each floor & \multirow[t]{6}{*}{300} & 70 & 210 \\
\hline Student research area & $6 \mathrm{~m}^{2} / 1$ researcher & 30 & & 6 & 180 \\
\hline Books display shelves & - & (300) $0.75 \times 2.1 \mathrm{~m}$ each & & 1.6 & 480 \\
\hline Online search areas & $1 \mathrm{PC} / 50$ students & 60 & & 2.5 & 150 \\
\hline Printing/copy centre & - & 2 & & 15 & 30 \\
\hline Reception counter & $35 \mathrm{~m}^{2} /$ counter & 1 & & 35 & 35 \\
\hline Staff research rooms & - & 40 & 115 & 6 & 240 \\
\hline Library manager room & $35 \mathrm{~m}^{2} / 1$ manager & 1 & 1 & 35 & 35 \\
\hline Staff offices & $15 \mathrm{~m}^{2} / 1$ staff & 5 & 5 & 15 & 75 \\
\hline Male students toilets & $1 \mathrm{WC} / 20$ students & 8 & 148 & 4 & 50 \\
\hline Female students toilets & $1 \mathrm{WC} / 20$ students & 8 & 148 & 4 & 50 \\
\hline Archiving and storage & - & 2 & - & 70 & 140 \\
\hline Maintenance workshop & - & 1 & - & 30 & 30 \\
\hline Meeting rooms & - & 1 & 6 & 15 & 15 \\
\hline Staff pantry & - & 2 & 14 & 10 & 20 \\
\hline Seminar rooms & - & 3 & - & 120 & 360 \\
\hline
\end{tabular}

Functionality: Ample considerations were given to the functionality and practicality of the master plan during its development. The functionality has been underpinned by a sound traffic impact assessment study for the surrounding site and traffic with solutions submitted to Urban Planning and Development Authority. Such study ensured the accessibility of the site without negative impact on the traffic in the area shown in Figure 13. The detailed plans have been developed with special attention to the requirements of each college of functional spaces, spatial relationships of the facilities, daylight and air quality ventilation, and other requirements for the disabled.

Safety and security: The access to the campus was developed with total adherence to the traffic regulations to

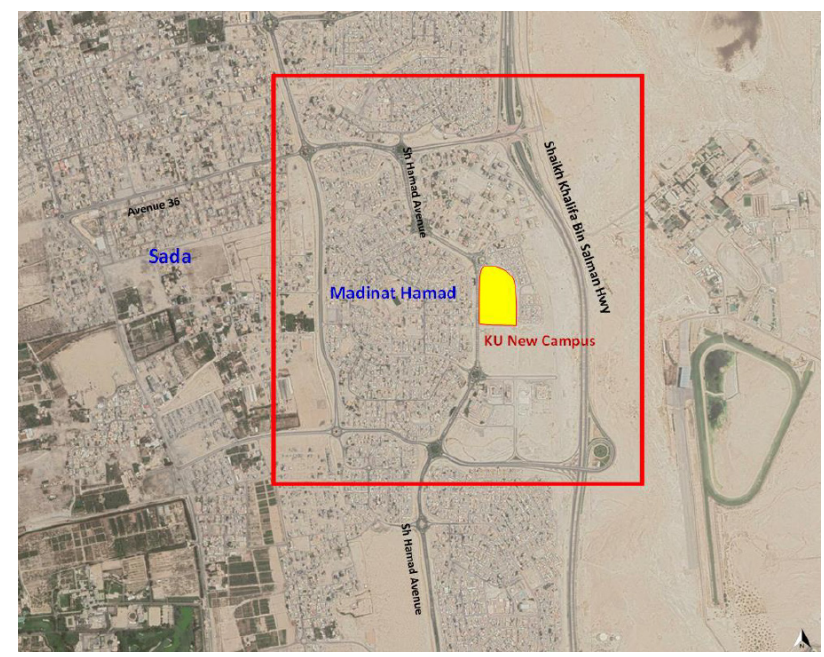

Figure 13. Traffic impact study area ensure safety, accessibility, and smooth circulation in and out of the campus. This was achieved with separate entrance and exit gates, speed down and acceleration lanes from and into highways, pedestrian walkways, and traffic wayfinding signages which offered noticeable features of the master plan as shown in Figure 14. The monitoring systems, gates control, guards' rooms, night lighting of the site and campus fencing were considered in the master plan development to secure the facilities. The detailed plans of the buildings consider providing peoples with safety trough adhering civil defence regulations in terms of firefighting system, emergency exits and fire resistance materials. The designs also consider providing security for the buildings through internal monitoring system that

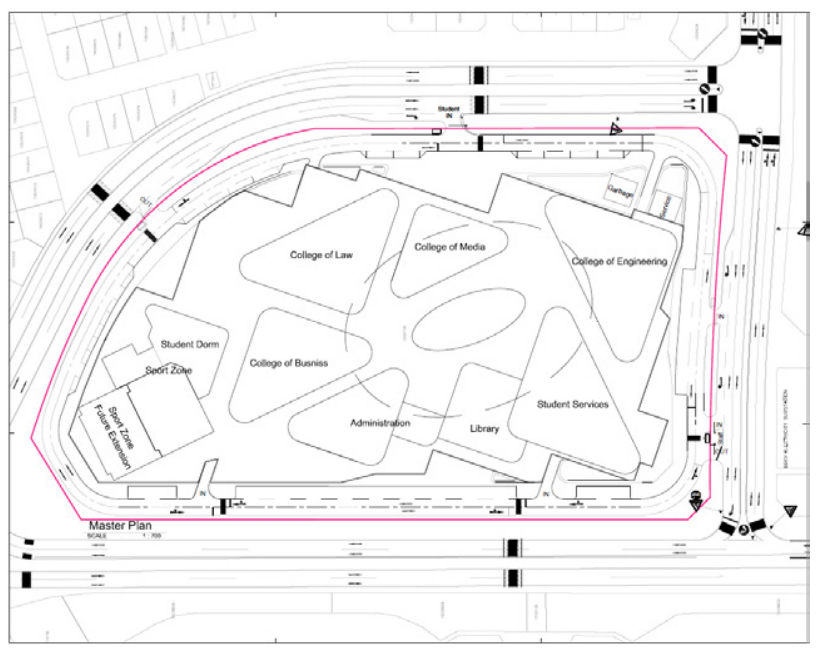

Figure 14. Master plan of the KU campus project 
record any unusual behaviour of strange peoples; secure building envelop that prevent any unusual access to the buildings; and entrance check-in points that ensure access for the authorized peoples only and conduct a medical check during the exceptional circumstances.

Cultural and social: National and regional cultural and tradition aspects have been a major consideration of the main design to respond to the societal context. This was achieved with the provision of privacy to the female dorm building, prayer rooms together with gender-based separation of recreation and relaxation areas.

Aesthetics: The concept of the design was inspired from the nature with great appreciation of the aesthetic aspects reflecting the aspiration of $\mathrm{KU}$ for its new campus. The interior spaces are designed to relate to the exterior space through natural lighting to all areas together with visual connection to landscape on open spaces which are formulated with the buildings' masses. The executive management of KU have the vision of developing exceptional interior designs that would develop a learning environment that is conducive to interactive learning, innovation, research, and community engagement.

Sustainability: In the main concept of the master plan, the configuration of the buildings was developed with different heights to maximize the shading effect on adjacent buildings and direct the wind to follow through the buildings' surrounding. The orientation of the roofing was, furthermore, designed to carry solar panels along the direction of the sun. Moreover, open spaces surrounding buildings were characterized by green roofs of the carparking structures. A central atrium with skylight was also developed at the centre of each academic building. The overall design forms and additions achieved sustainability through minimizing the energy consumption and increasing the energy efficiency.

\section{Conclusions and recommendations}

In this paper a taxonomy is proposed for planning and designing HE campuses that would provide a guide or benchmark and raise the awareness of the various stakeholders in the process. The authors proposed model of taxonomy for planning of HEIs campus. This taxonomy is inspired from bloom's taxonomy model and required its reflection on planning domains, implementation phases, and necessary planning considerations. The authors proposed the presented model in which the order and level of complexity for each campus planning domain is developed. The relationship between domains is ordered, from base to top of the pyramid, according to a followed process from educational programming to detailed design. The process is firstly started with the educational programming domain which is applied for all academic programs using strategic information. Campus planners have minor

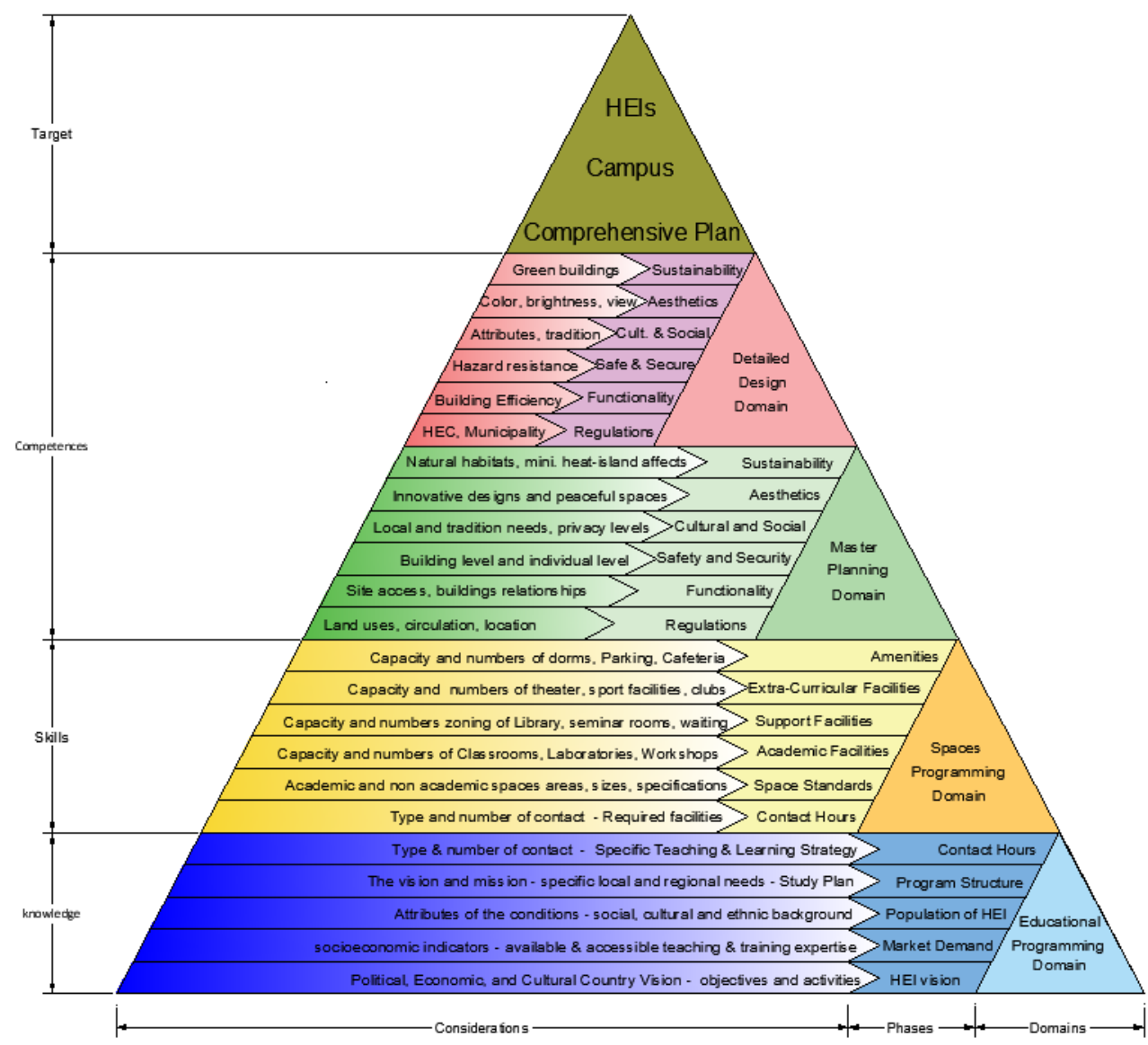

Figure 15. Taxonomy model of HEIs campus planning 
contributions in this domain and are only concerned with simple actions. Educational planners, however, have most input in this domain with considerations for developing vision, studying market demands, survey the HEI population, design program structure and determining the required contact hours. Therefore, it is fair to say that for campus planners, the educational programming needs knowledge rather than skills and competences. Secondly, campus planners apply their knowledge of the educational programming and analyse program structure and contact hours to develop the campus space programming to determine the required various facilities and standards. Therefore, the space programming is similar in nature to skills in bloom's taxonomy. Lastly, both master planning and detailed planning require advanced competencies from the campus planners. They study all design problems and create the solutions to address regulations, function, safety and security, culture and social context, aesthetics, and sustainability.

This approach is supported by the transformation from teacher-centered to student-centered learning theories in the Bologna declaration in 1999 which encourages the competitiveness of institutions to attract students and faculty. Proper campus planning and design should support this latter theme by providing adequate and attractive learning environments. The proposed taxonomy is meant to serve as a roadmap for designers and stakeholders involved in the planning and design phases of campuses as shown in Figure 15. The steps and arguments presented shed light on the expected efforts during the various stages of the campus design process. The proposed taxonomy involves the key processes, starting with educational programming and ending with the development of building designs.

The above proposed taxonomy model is applicable for to a variety of cultures and contexts. It presents a detailed roadmap for campus planners and developers. They still need, however, to consider environment, culture, context and all circumstances of their project as variables inputs for planning and designing the HEI campus.

\section{References}

Al-Atiqi, I. T. M. (2008). Guide to the criteria for assessment of sites and buildings of Private Universities. General Secretariat of the Private Universities Council, Technical Committee, Ministry of Higher Education of The State of Kuwait.

Bloom, B. S. (1956). Taxonomy of educational objectives, handbook 1: cognitive domain. Longman.

Campus News. (2009, April 3). Decrease in crime on UT campus thanks to outreach efforts. https://news.utk.edu/2009/04/03/ decrease-in-crime-on-ut-campus-thanks-to-outreach-efforts/

Campus Planning and Landscape Guidlines. (2011, August 19). https://www.pomona.edu/sites/default/files/planning_guidelines.pdf

Chapman, P. M. (2006). American places: in search of the twentyfirst century campus. Rowman and Littlefield Publishers.

Chylinski, M. (2010, January). Campus safety. Private Colleges and Universities and Careers and Colleges.
Coulson, J., Roberts, P., \& Taylor, I. (2018). University trends: contemporary campus design. Routledge, Taylor \& Francis Group. https://doi.org/10.4324/9781315213606

Dalton, L. C., Hajrasouliha, A. H., \& Riggs, W. W. (2018). State of the art in planning for college and university campuses: site planning and beyond. Journal of the American Planning Association, 84(2), 145-161. https://doi.org/10.1080/01944363.2018.1435300

David, N. J. (2003). Building type basics for college and university facilities (S. A. Neuman, Ed.). John Wiley \& Sons, Inc.

El-Ansari, W., \& Stock, C. (2010). Is the health and wellbeing of university students associated with their academic performance? Cross sectional findings from the United Kingdom. International Journal of Environmental Research and Public Health, 2(7), 509-527. https://doi.org/10.3390/ijerph7020509

Glare, P. G. (Ed.). (1982). Oxford Latin dictionary. Oxford University Press.

Gloster II, A. S., \& Saltzberg, S. A. (1996). Multimedia and asynchronous learning: changing the support model for information technologies services. Cause/Effect, 2(4), 27-29, 34-36.

Gul, A., Uzun, Ö. F., \& Keleş, E. (2016). Recreational demand and trends in the campus students and lecturers of Süleyman Demirel University. Journal of Architecture Sciences and Applications, 1(1), 26-43. https://doi.org/10.30785/mbud.282560

Hossein, A. (2002). Impact of the internet on learning and teaching. USDLA Journal, 16(3).

Jimenez, R. (2003). Space planning guidelines (2nd ed.). Australasian Association of Higher Education Facilities Officers (AAPPA). https://www.academia.edu/14877519/SPACE_ PLANNING_GUIDELINES_Edition_2

Loukaitou-Sideri, A., Medury, A., Fink, C., Grembek, O., Shafizadeh, K., Wong, N., \& Orrick, P. (2014). Crashes on and near college campuses: a comparative analysis of pedestrian and bicyclist safety. Journal of the American Planning Association, 80(3), 198-216. https://doi.org/10.1080/01944363.2014.978354

NBBJ. (2015). NBBJ science and education brochure. ISSUU. https://issuu.com/nbbj/docs/nbbj_science_and_education_ brochure

Office of University Architects for Facillities Planning. (2018). Architectural campus planning principles. UGA. https://www. architects.uga.edu/sites/default/files/documents/standards/ architectural_campus_planning_principles.pdf

Quinn, P. D., \& Duckworth, A. L. (2007). Happiness and academic achievement: evidence for reciprocal causality. The Annual Meeting of the American Psychological Society, 24-27.

Resolution No. (1127)/2017 for regulations of Sport facilites in HEIs. (2017). HEC, Minstry of Education.

Resolution No. (2)/2007 for admin and academic affaires of HEIs. (2007). HEC, Minstry of Education.

Resolution No. (4)/2007 for regulations of HEIs buildings. (2007). HEC, Minstry of Education.

Schulz, R. (2017). Statmnet of design principles of SDSU campus. SDSU.

Stack, P., \& Leitch, A. (2020). Chapter 3: integrated budgeting and planning. In L. Goldstein, Linking resource allocation to planning and assessment (Vol. 25, pp. 25-39). Society for College and University Planning.

The sustainable sites initiative: guidelines and performance benchmarks. (2020, December 15). https://digital.library.unt.edu/ ark:/67531/metadc31157/

Thomas, J. L. (2014, April 28). Bloom's taxonomy: education. https://www.britannica.com/topic/Blooms-taxonomy 
Troost, S. (2020). Campus planning. https://www.scup.org/planning-type/campus-planning/

Turland, N. J., \& Wiersema, J. H. (2018). International Code of Nomenclature for algae, fungi, and plants. Koeltz Botanical Books. https://doi.org/10.12705/Code.2018

Turner, P. V. (1984). Campus: An American planning tradition. Cambridge. The MIT Press.

Wedge, C., \& Kearns, T. (2005, July/August). Creation of the learning space: catalysts for envisioning and navigating the design process. Educause Review, 32-38. https://er.educause. edu/-/media/files/article-downloads/erm0541.pdf

Yerli, O., \& Ozdede, S. (2017). Design process of a campus plan: a case study of Duzce University Konuralp Campus. International Journal of Engineering Research and Application, 7(4), 50-59. https://doi.org/10.9790/9622-0704015059

Young, J. R. (2010, July 24). Reaching the last technology holdouts at the front of the classroom. https://www.chronicle.com/article/College-20-Reaching-the-Last/123659 